اتجاهات الثباب الريفي نحو العمل الززاعي والمشاركة في أنثطة خدمة البيئة الريفية بمركز

$$
\begin{aligned}
& \text { إيتاى البارود بمحافظة البحيرة }
\end{aligned}
$$

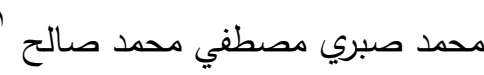

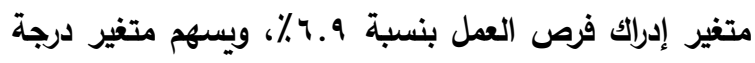

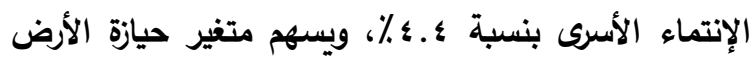

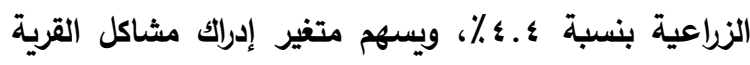

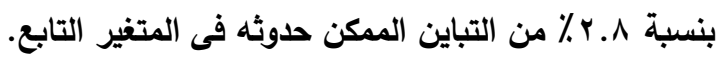

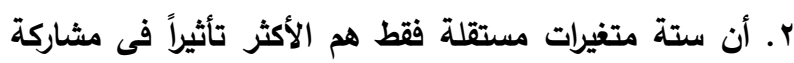

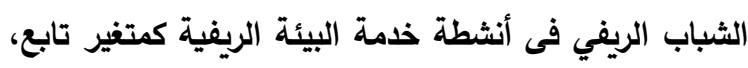

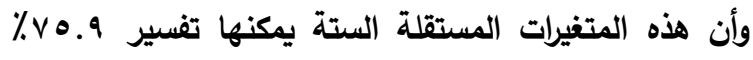

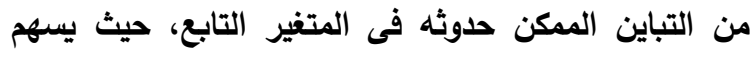

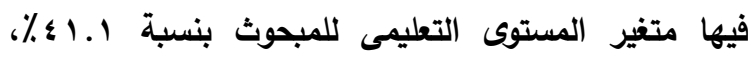

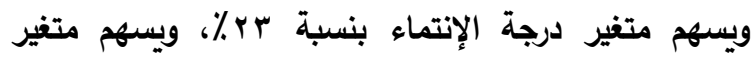

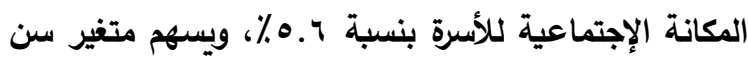

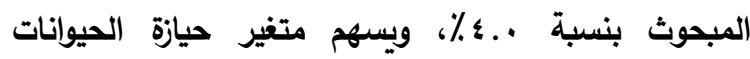
الززاعية بنسبة r. ا٪، ويسهم متغير عدد أفراد الأسرة بنسبة 9 . ٪ من التباين المكن حدوثه فى المتغير التابع. الكلمات المفتاحية: الثباب الريفى - العمل الزراعى - أنثطة

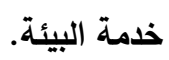

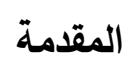

أدى الاستخدام المفرط للتقنيات الزراعية المتعددة بهدف

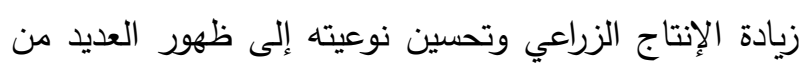

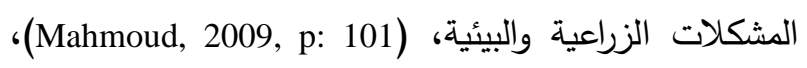

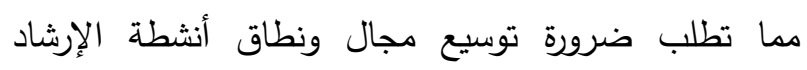
الزراعى فى مواجهة تلك المشكلات، باعتباره أحد أهم الآليات الإنشاد

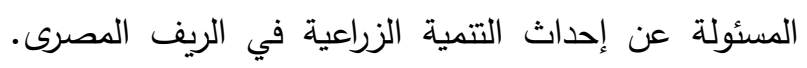

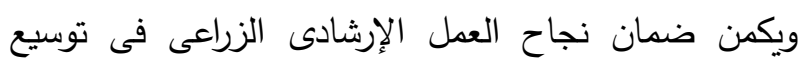

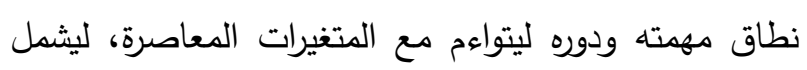
الإرشاد البيئي، وإرشاد الثباب الريفى، والإرشاد الزراعى لئي العاصرة ليشي

$$
\text { الملخص العربى }
$$

تمثل الهذف الرئيسى لهذا البحث فى التعرف على اتجاهات

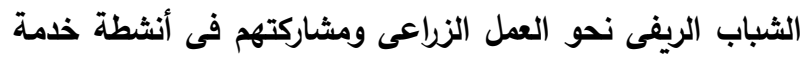

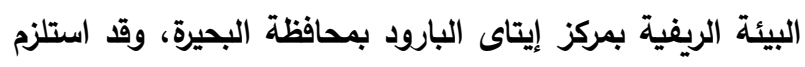
ذلك تحقيق الأهداف الفرعية الآتية:

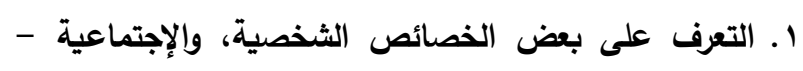
الإقتصادية، والنفسية، والإتصالية المميزة للثباب الريفي الإتيفى المبحوثين. r. التعرف على إتجاهات الثباب الريفى المبحوثين نحو العمل

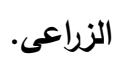
r. التعرف على درجة مشاركة الثباب الريفى المبحوثين في أنثطة خدمة البيئة الريفية. ؛. دراسة المتغيرات المرتبطة والمؤثرة على كل من إتجاهات

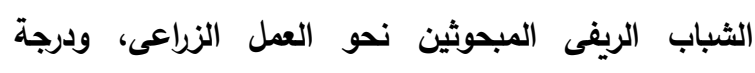
مشاركتهم في أنثطة خلمة البيئة الريفية. وتم جمع البيانات باستخام الاستبيان بالمقابلة الثخصية

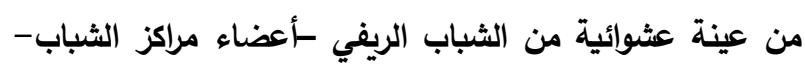

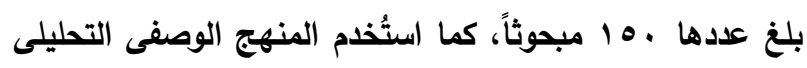

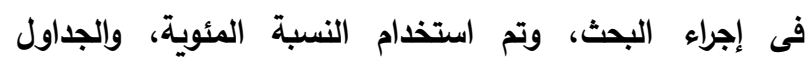

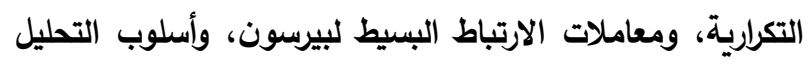
الإنحدارى المتعدد بالإضافة. وقد توصل البحث إلى العديد من النتائج أبرزها ما يلى: 1. أن خمسة متغيرات مستقلة فقط هم الأكثر تأثيراً فى الإتجاه نحو العمل الزراعى بين الثباب الريفي المبحوثين كمتغير

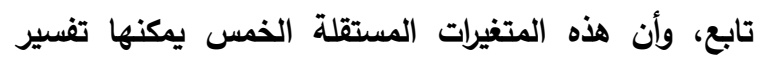

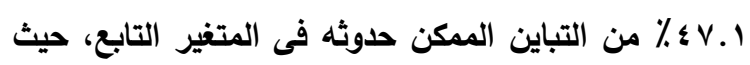

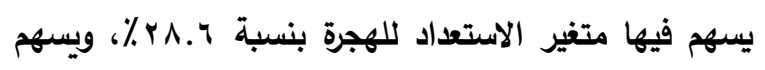

'قسم الارشاد الزراعي -كلية الزراعة جامعة الاسكندرية

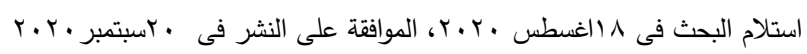




\section{المثكلة البحثية}

يشه عالم اليوم تطوراً سريعاً فى المجال الزراعى نتيجة للإنفجار المعرفي والتقدم التقني، وقد صاحب هذا التطور

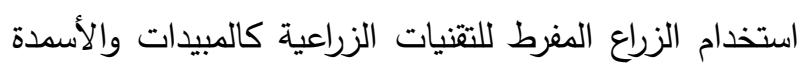
المصنعة من أجل زيادة الإنتاجية الزراعية، والتحكم في الظروف البيئية الذى أعطى القدرة على زراعة نفس الإسله المحصول لأكثر من مرة وبشكل متتالى لنفس الرقعة الزراعية، والارتقاء بمتوسطات انتاجية الفدان من المحاصيل الزراعية، فى الوقت الذى يلاحظ فيه تفتت وتقزم الحيازات

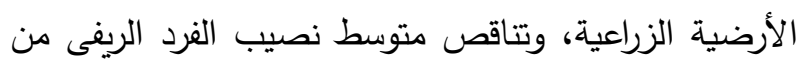
كل من الأرض الزراعية والدخل الزراعى، وتزايد أعداد الثباب الريفى الملتحقين بالمراحل التعليمية المختلفة والخريجين بينهم، ووصول الخدمات الإذاعية والتليفزيونية إلى ربوع لرعئ الريف المصرى، وزيادة مستخدمى الثبكة العنكبوتية ومنصات التواصل الإجتماعى بين الشباب الريفى، ومحدودية فرص العمل المتاحة حالياً فى المجتمعات الريفية، مما أدى لإنى إلى ظهور بعض القيم والاتجاهات المستحدثة بين الثباب الريفى، حيث لاحظ الباحث بحكم أصوله الريفية واحتكاكه واتصالاته بالعديد من الثباب فى مركز إيتاى البارود تغير

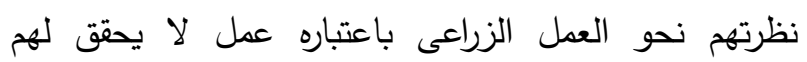
مستوى المعيشة الذى يصبون إليه، وبالتالى زيادة تطلعاتهم للهجرة الخارجية، أو النزوح إلى المناطق الحضرية سعياً وراء

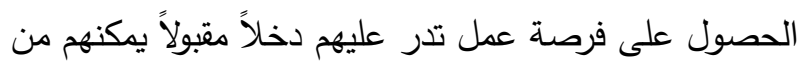
تحقيق طموحاتهم فى مستوى معيشة أفضل.

ولا ريب أن الثباب الريفى يُعد جزءً هاماً من سكان المجتمع الريفى، ومن ثم يصعب إحداث نهوض شامل فى المجتمع الريفى دون إدراج عنصر الثباب كمكون أساسى في برامج التتمية الريفية، خاصة وأن الثباب يتمتعون غالباً بالقوة والطاقة والرغبة في التغيير والاستعداد لتبنى القيم الجديدة في مواجهة ما هو سائد من قيم تقليدية، وعليهج تعقد الكثير من ون
التسويقى، والإرشاد الزراعى الإروائى...إلخ من الأنشطة

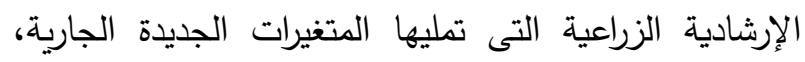

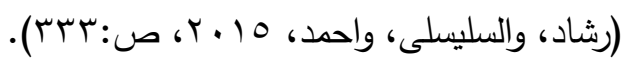
ويُعد الشباب بمثابة الأساس الذي يبني عليه التقدم في كافة مجالات الحياة، وهم أكثر فئات المجتمع قدرة ونشاطاً وإصراراً على العمل والعطاء، ولديهم الإحساس والرغبة في التغيير مما يجعلهم أهم سبل علاج مشكلات المجتمع،

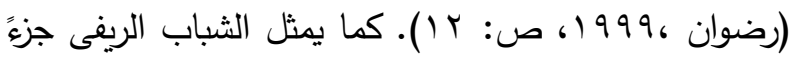
هاماً من سكان المجتمع الريفى، ومن الصعوبة إحداث نهوض شامل فى المجتمع الريفى دون إدراج عنصر الثباب كمكون أساسى في برامج التتمية الريفية، خاصة وأنهم يتمتعون غالباً بالقوة والطاقة والرغبة في التغيير والاستعداد لتبنى القيم الجديدة في مواجهة ما هو سائد من قيم تقليدية،

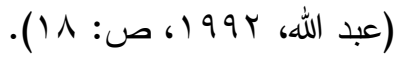

ولما كان الثباب الريفى هم أحد الفئات المستهدفة من الإرشاد الزراعى فمن ثم فإنه يسعى للوصول إلى هؤلاء الشباب وإمدادهم بالمعارف الجديدة المفيدة، وإكسابهم المهارات المحسنة والقيم والإتجاهات الإيجابية المقبولة لصالحهم كأفراد ولصالح أسرهم وبيئتهم الريفية ومجتمعهم، وذلك بصورة مباشرة أوغير مباشرة من خلال التعاون والتتسيق والتكامل مع المنظمات الثبابية الريفية وغيرها من المنظمات

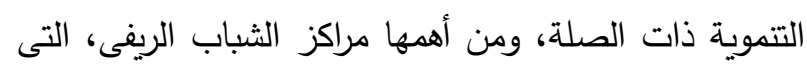
بدورها تضم وترعى وتؤثر في الثباب الريفى، وتهدف إلى تتمية قدراتهم وإمكانياتهم، وتتظيم الفعاليات المختلفة سواء كانت رياضية أوفنية أوتقافية، كجزء من أولوياتها واهتماماتها الموجهة للشباب بغية تطويرهم نحو الأفضل، وبث روح العمل الجماعي ونشر ثقافة العمل التطوعي بينهم، وغرس القيم الإيجابية، وحمايتهم من الأفكار السلبية كالطائفية والفئوية، إلى جانب محاربتها للعادات والتقاليد البالية، واستبدالها بالعادات والتقاليد التي تتسجم مع التراث الحضاري لمجتمعهم، (Mahmoud, 2009,p:101). 
117 محمد صبري مصطفي محمد صالح.: اتجاهات الثباب الريفي نحو العمل الزراعي والمشاركة في أنثطة خدمة البيئة الريفية.... الآمال في النهوض بمجتمعاتهم، (عبد الله، ب991، ص:ع. دراسة المتغيرات المرتبطة والمؤثرة على كل من إتجاهات الشباب الريفى المبحوثين نحو العمل الزراعى، ودرجة

مشاركتهم في أنثطة خدمة البيئة الريغية.

\section{الاستعراض المرجعى}

يثير تقرير التنمية الريفية لعام 19 ـ ب إلى أن أكثر من نصف شباب الدول النامية ومن بينها مصر يعيشون في المناطق الريفية، وأن تلك الكتلة البشرية من الثباب لديها

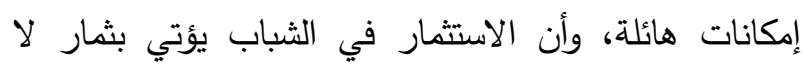
حصر لها من حيث الحد من الفقر، وتهيئة فرص للعمل، والأمن الغذائي والتغذوي، ويؤكد التقرير على أن هؤلاء الثباب من الجنسين هم السبيل إلى تحقيق أهداف التتمية المستدامة بحلول عام .r.Y، (الصندوق الدولي للتتمية

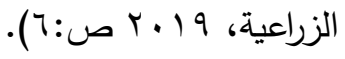
وفى هذا الصدد تؤكد رضوان (999 1، ص: r I) أن الثباب بصفة عامة أكثر فئات المجتمع قدرة ونشاطاً وإصراراً على العمل والعطاء، والرغبة في التغيير مما يجعلهم أهم سبل علاج مشكلات المجتمع. ومن الصعب إحداث نهوض شامل

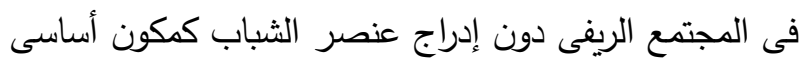
في برامج التمية الريفية، فعليهم تعقد الكثير من الآمال في النهوض بمجتمعاتهم، (عبد الله ، ب99 (، ص: ب (1). وتعد مراكز الثباب أحدى المؤسسات الإجتماعية التربوية الإختيارية التي تساعد الشباب علي تكوين الشخصية المتزنة من خلال ممارستهم للأنشطة الإجتماعية والرياضية والثقافية والترويحية، وهي إحدي المؤسسات المهنية التي تمارس فيها الخدمة الإجتماعية بهدف خدمة البيئة والحفاظ عليها، وتتمية قدرات وطاقات الثباب وتتمية الوعي السياسي والثقافي، وإتاحة الفرصة للشباب للمشاركة الفعالة والجادة في المشروعات البيئية والخدمة العامة التي يقدمها مركز الثباب

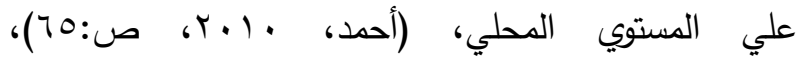

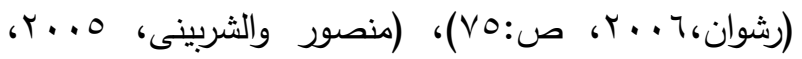

ولكى يقوم الثباب الريفى بالدور المرجو منهم فى إحداث

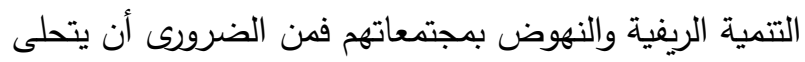
هؤلاء الثباب بالقيم والإتجاهات الإيجابية نحو العمل الزراعى والبيئة الريفية والمجتمع المحلى. وبالرغم من ذلك يلاحظ أن

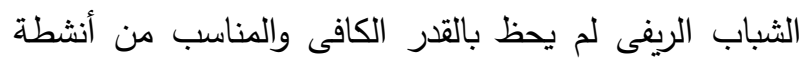
وخدمات الجهاز الإرشادى الزراعى بصورة مباشرة أو غير مباشرة من خلال التعاون والتتسيق والتكامل مع المنظمات المعنية بالثباب الريفى، ولما كانت مراكز الثباب الريفى هى

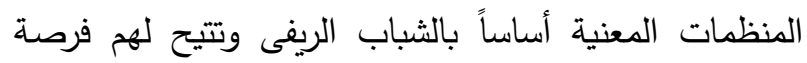
الإنضمام إليها، والاستفادة من خدماتها التربوية البدنية والثقافية والبيئية والاجتماعية وغيرها، فمن ثم فقد أجرى هذا البحث للتعرف على كل من اتجاهات الثباب الريفى الذين يتمتعون بعضوية قائمة فى مراكز الشباب الريفى نحو العمل الزراعى، ومشاركتهم فى أنشطة المحافظة على البيئة الريفية فى مركز إيتاى البارود بمحافظة البحيرة.

\section{الاهداف البحثية}

تمثل الهدف الرئيسى لهذا البحث فى التعرف على

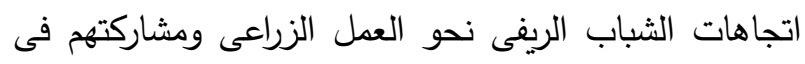
أنشطة المحافظة على وصيانة البيئة الريفية بمركز إيتاى البارود بمحافظة البحيرة، وقد استلزم ذلك تحقيق الأهداف

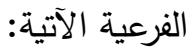

ا ـ التعرف على بعض الخصائص الثخصية، والإجتماعية - الإقتصادية، والنفسية، والإتصالية المميزة للشباب لـابل

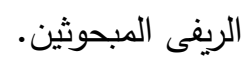

r. التعرف على إتجاهات الثباب الريفى المبحوثين نحو

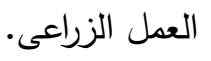

r. التعرف على درجة مشاركة الثباب الريفى المبحوثين في أنشطة خدمة البيئة الريفية. 


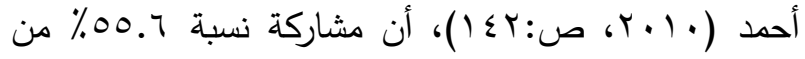
الثباب المبحوثين في البرامج التطوعية لخدمة البيئة وتتمية قريتهم ما بين منخفضة ومتوسطة، وأظهرت دراسة الفيل

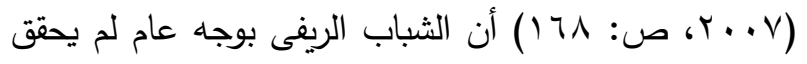
القدر المعقول من المنجزات الثبابية الريفية التي تساعده على الاستقرار وتحقيق ذاته في القرية والمجتمع بصفة عامة،

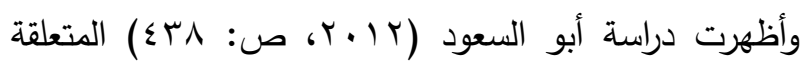
بالتفضيلات المهنية للشباب الريفى ببعض قرى محافظة الغربية أن OV \% من المبحوثين قد أقروا بأهمية الوظيفة الحكومية عن العمل في الزراعة لكون الوظيفة الحكومية مصدراً للمكانة الإجتماعية المرموقة.

\section{الأسلوب البحثي}

المتغيرات البحثية وطرق قياسها (أ) المتغيرات المستقلة

ا ـ المبحوث: ويقصد به في هذا البحث الثاب الذي يتمتع بعضوية قائمة فى مركز الثباب الريفى ويتراوح سنه من 10 10

r. سن والاد المبحوث: ويقصد به فى هذا البحث سن والد المبحوث لأقرب سنة ميلادية.

r. سن المبحوث: ويقصد به فى هذا البحث سن المبحوث

$$
\text { لأقرب سنة ميلادية. }
$$

ع. المستوى التعليمى لوالد المبحوث: ويقصد به فيى هذا

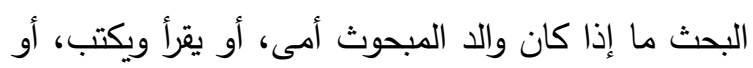
إبتدائى، أو إعدادى، أو ثانوى، أو جامعى، وقد تم التعبير

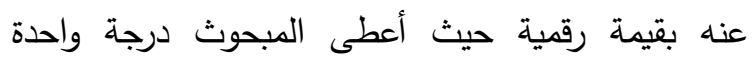
للأمى، ودرجتان ليقرأ ويكتب، وثلاث درجات للإبتدائى،

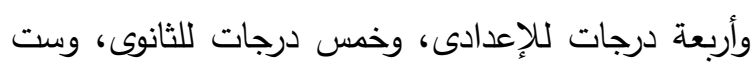

$$
\text { درجات للجامعى. }
$$

هـ المستوى التعليمى للمبحوث: ويُقصد به في هذا البحث

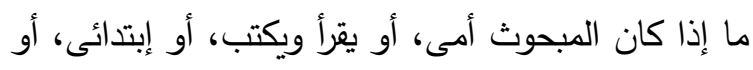

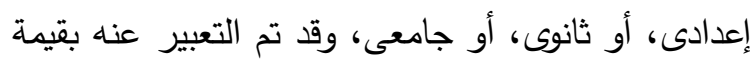

ويرى الجندى والصوفى (9919 (، ص: 7) ) والدباح

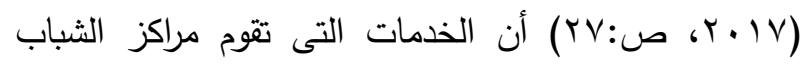
بتقديمها للشباب في شكل برامج وأنشطة من شأنها مواجهة مشكلات الثباب وإحداث تغيير في الثباب من خلال إكتساب العديد من المهارات وتتمية مواهبهم مستغلاً لكافة

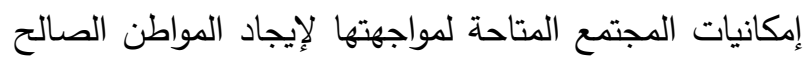
القوي القادر على مواجهة المشاكل والمشاركة في تتمية بلده.

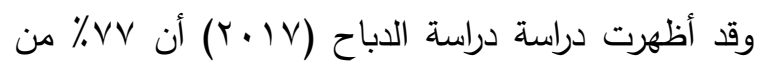

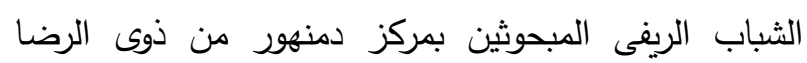

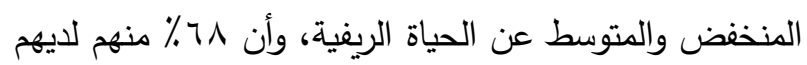

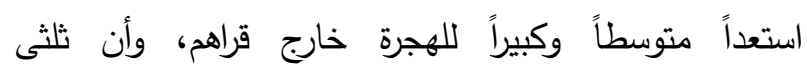
المبحوثين من ذوى درجة المشاركة المنخفضة والمتوسطة فى مولى

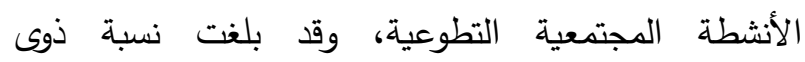

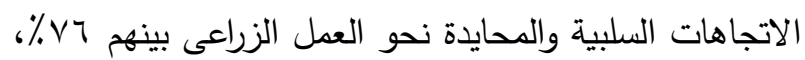

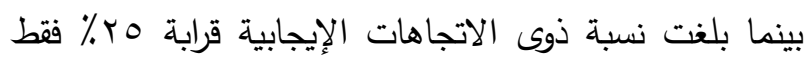
من جملة المبحوثين، كما تبين من دراسة الدباح أيضاً وجود علاقة إرتباطية بين اتجاهات الثباب الريفى المبحوثين نحو العمل الزراعى ومتغيرين مستقلين فقط هما: مستوى الطموح،

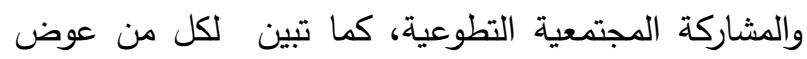

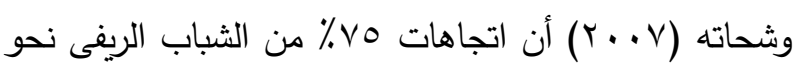
العمل الزراعى بمحافظتى البحيرة والمنيا كانت محايدة، وأن الاتجاه نحو العمل الزراعى يرتبط معنوياً عند المستوى لهدي الإحتمالى 0... مع كل من عمر المبحوث، والدخل

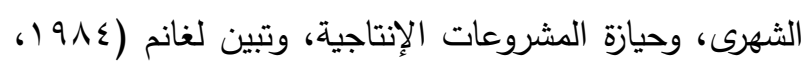

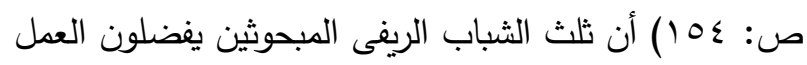
الحكومى، ويفضل 0.0ء ٪ شراء الأراضى الزراعية ويفضل

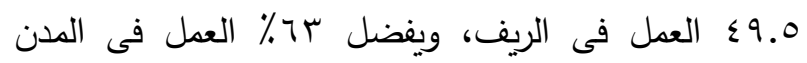

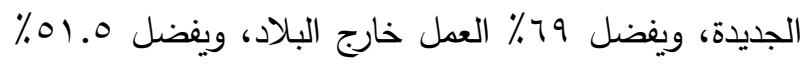
مشاركة الأهالى فى مشروعات التتمية المحلية. كما أظهرت بعض الدراسات تراجع مشاركة الشباب الريفى في الأنشطة التتموية في قراهم، فقد أظهرت دراسة 
رقمية حيث أُعطى المبحوث درجة واحدة للأمى، ودرجتان مدى التعرض: دائما (ץ درجات)، أحياناً (درجتان)، نادراً

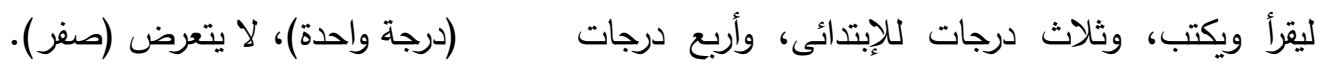
للإعدادى، وخمس درجات للثانوى، وست درجات مدى الاستفادة: كبيرة (ץ درجات)، متوسطة (درجتان)،

$$
\text { قليلة (درجة واحدة)، منعدمة (صفر). }
$$

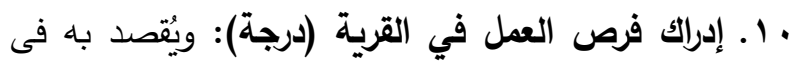
هذا البحث إدراك المبحوث لمدى توفر فرص العمل المتاحة في القرية، وقد تم التعبير عنه بقيمة رقمية أمكن

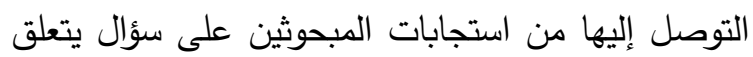
بالمجالات المختلفة للعمل المتوفرة بالقرية، وقد تم إعطاء درجة واحدة لكل مجال يذكره المبحوث. 1 ا ـ الاستعداد للهجرة، ويُقصد به فى هذا البحث موقف المبحوث من حيث الموافقة أو الرفض على مضمون أربع عبارات تتعلق بهذا الثأن، وهى: ما إذا كانت مؤهلاته وقدراته تؤهله للسفر للعمل بالخارج، وما إذا كانت فرص إنس العمل بالخارج أفضل له منها بالداخل، وما إذا كان يبحث عن فرصة للهجرة للعمل بالخارج، وما إذا كانت أسرته باله تُشجعه على السفر للخارج، وذلك على مقياس ثثائى (غير موافق، وموافق) حيث أعطى المبحوث صفر لعدم الموافقة، ودرجة واحدة للموافقة. r I ـ المكانة الإجتماعية للأسرة: ويُقصد بها فى هذا البحث تقدير المبحوث الذاتي للمكانة الاجتماعية لأسرته، ما إذا لإنا كانت مكانة منخفضة، أو متوسطة، أو مرتفعة، وقد أعطى درجات ) ، ب، ب على الترتيب لكل منهما. rا ــرجة الإنتماء الأسرى: ويُقصد بها فى هذا لـى البحث درجة موافقة المبحوث على تسع عبارات تتعلق بهذا الثأن، وهى: ما إذا كانت الأسرة تجتمع بشكل دوائم

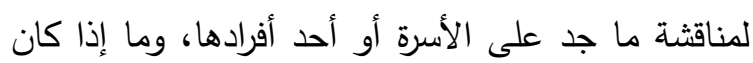
أفراد الأسرة يحرصون على تمضية أو قات الفراغ معاً، وأيضاً ما إذا كانوا يخططون للقيام ببعض الأنرون النشطة الجماعية معاً، وما إذا كان هناك قرب وتلاحم وإرتياح للعمل مع أفراد الأسرة، بالإضافة لحرص أفراد الأسرة

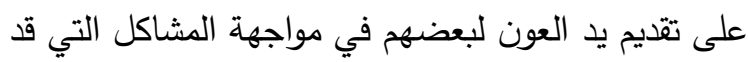

7. عدد أفراد الأسرة: ويقصد به فى هذا البحث عدد أفراد أسرة المبحوث الذين يعيشون معاً معيثة اجتماعية وإقتصادية مشتركة.

V. الحيازة الأرضية الزراعية: ويُقصد بها فى هذا البحث

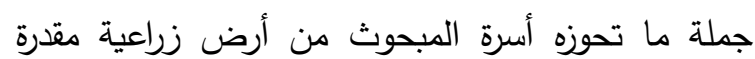
بالقيراط.

^. الحيازة الحيوانية الزراعية: ويُقصد بها فى هذا البحث عدد ما تمتلكه أسرة المبحوث من رؤوس أبقار وجاموس

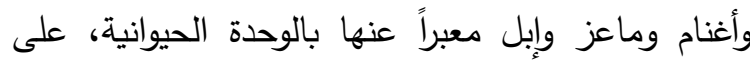
أساس أن كل من الثور، والفحل، والجاموسة الكبيرة

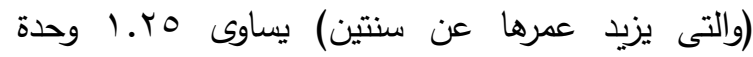
حيوانية، والجاموسة المتوسطة (من سنة إلى أقل سنتين) 7. . . وحدة حيوانية، والجاموسة الصغيرة (أقل من سنة) r.. وحدة حيوانية، والبقرة الكبيرة والحصان (التى يزيد عمرها عن سنتين) تساوى وحدة حيوانية، والبقرة المتوسطة (أقل من سنتين) نصف وحدة حيوانية، والبقرة الصغيرة

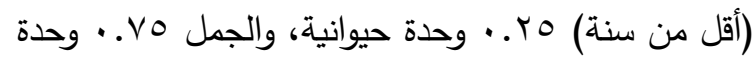
حيوانية، ورأس الغنم ا..

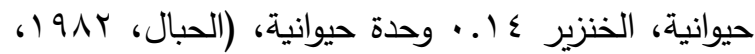
ص: ص: (1)

9. الانفتاح الإعلامي: ويُقصد به فى هذا البحث مدى تعرض المبحوثين لكل من الصحف والمجلات، والبرامج التليفزيونية، والبرامج الإذاعية بالراديو، والمواقع

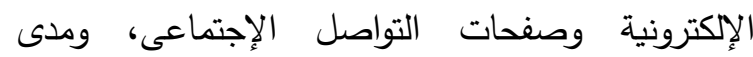
استفادتهم منها، وقد تم التعبير عنه بقيمة رقمية أمكن التوصل إليها من استجابات المبحوثين على سؤالين

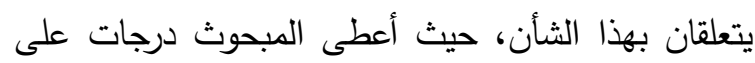
النحو التالى: 
العمل الزراعى عمل يزيد الفرد قرباً من الله، وأن العمل

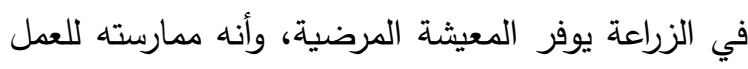

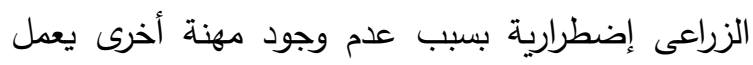

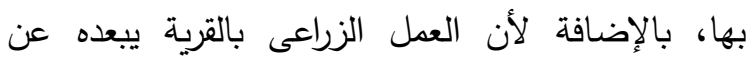

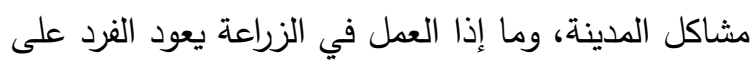

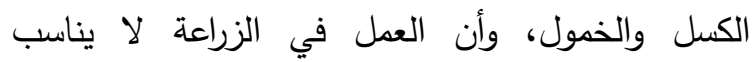
الأشخاص المتعلمين، كما يؤدى العمل في الزراعة إلى

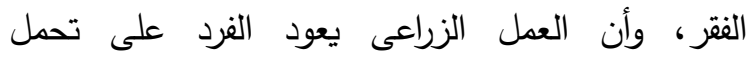
المسئولية، وما إذا كان يتمنى السفر إلى المدينة للإبتعاد

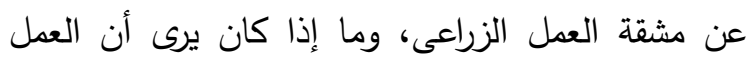

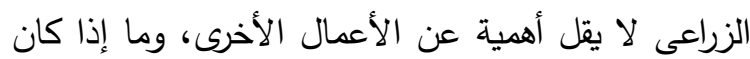

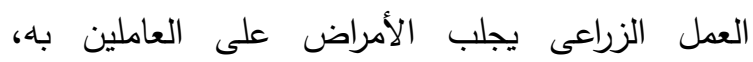
بالإضـافة لإفتخاره بعمله في الزراعة، وما إذا كان يرى أن بـان

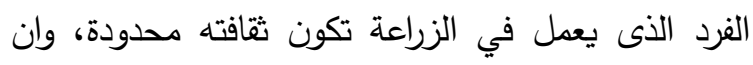

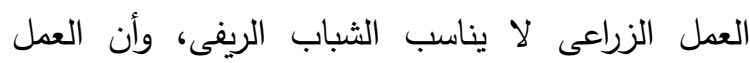
الزراعى يناسب كل من هم في سن العمل، وان العمل الزراعى لا يعطيه فرصة للعيش في مناطق أخرى، وأن العمل في الزراعة يعتبر من أفضل مصادر الدخل، وأن

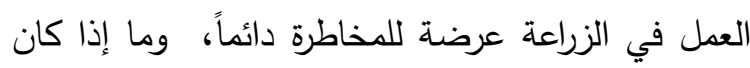

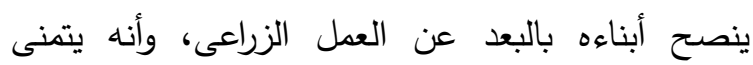

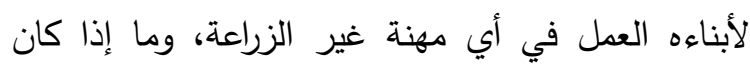
العمل في زراعة الأرض وتربية المواشى يمثل له عيشة

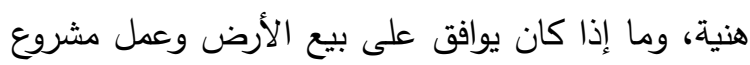
بثمنها، وموافقته على تحويل الأراضى الزراعية لمساكن ومصانع، وما إذا كان يتمنى شراء وتملك أرض زراعية،

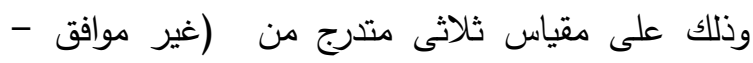

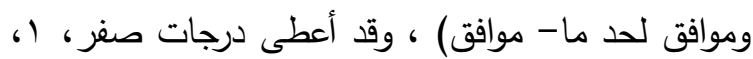

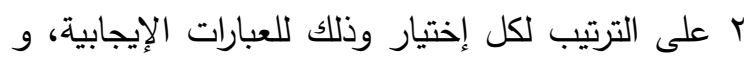
r - 1 - صفر للعبارات السلبية.

r. المشاركة فى أنثطة خدمة البيئة الريفية: ويقصد به فى الى هذا البحث درجة مشاركة المبحوثين فى عشرة أنشطة تتتعلق بخدمة البيئة الريفية، من حيث تتظيف وتجميل
تواجه أياً منهم، وقدرة أفراد الأسرة على الإشتراك فى لى أنشطه لا ترتبط بها، وما إذا كان يفضل أن يشارك أحد

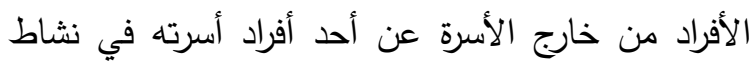

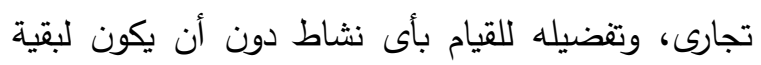

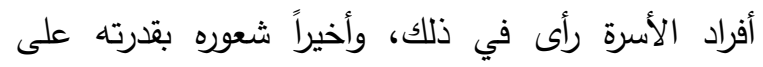
الإعتماد على ذاته وعدم تفضيله لتلقى الدعم من قبل أسرته، وذلك على مقياس ثلاثى متدرج من غير موافق-

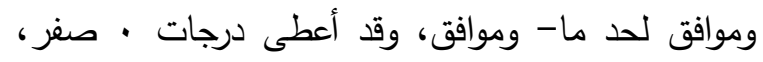
ا، Y على الترتيب لكل إختيار وذلك للعبارات الإيجابية، والعكس للعبارات السلبية. ـ اـ إدراك مشاكل القرية (درجة): ويُقصد به فى هذا البحث مدى إلمام المبحوث بمشكلات القرية، وتم التعبير عنه بقيمة رقمية تم التوصل إليها من خلال إجابات المبحوثين

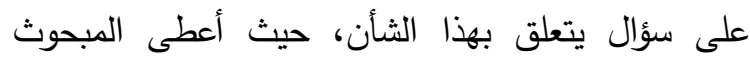
درجة لكل مشكلة يذكرها. (ب) المتغيرات التابعة: - (ب) ا ـ الإتجاه نحو العمل الزراعى: ويقصد به فى هذا البحث

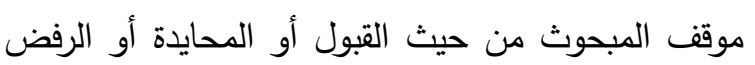
لمضمون (·r) عبارة تتعلق بأهمية وقيمة وإيجابيات وسلبيات العمل الزراعى والمردود الاقتصادى والاجتماعى لهیى والنفسى للعمل الزراعى على أفراد الأسرة، ونظرة الآخرين للمشتغلين به، والفرص التى يتيجها العمل الزراعى

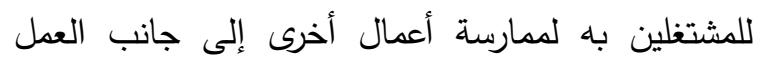
الزراعى، وتتويع مصادر الدخل الأسرى وهى: ما إذا كان

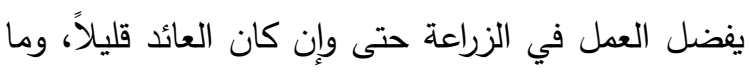
إذا كانت الوظيفة بصفة عامة أفضل لله من العمل بالزراعة، وتفضيله لعمل آخر عن العمل في الزراعة، وما

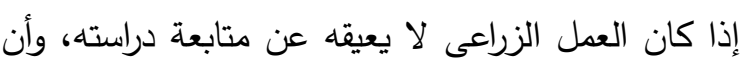
ممارسة العمل الزراعى ترفع من قيمة الفرد، وشعوره بالحرج عندما يخبر الآخرين أنه يعمل بالزراعة، وما إذا منا لترفي

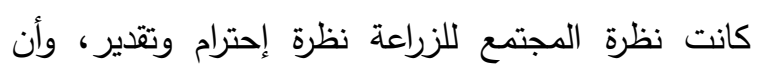


121 محمد صبري مصطفي محمد صالح.: اتجاهات الثباب الريفي نحو العمل الزراعي والمشاركة في أنشطة خدمة البيئة الريفية....

(Y) ودرجة الإنتماء الأسرى، (T) وإدراك مشاكل القرية، وذلك فى ظل التأثيرات التبادلية لهذه المتغيرات. وقد تم قياس الفرض السابق فى صورته الصفرية التى تتص على عدم وجود علاقة بين المتغير التابع، والمتغيرات المستقلة المدروسة.

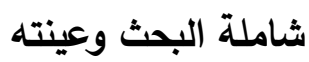

أشتملت شاملة البحث على جميع أعضاء مراكز الشباب بركز ايتاى البارود بمحافظة البحيرة والبالغ عددها سب مركزا، وقد تم إختيار ثلاثة مراكز شباب منها بطريقة عشوائية، وهى مركز شباب قرية امليط، ومركز شباب قرية

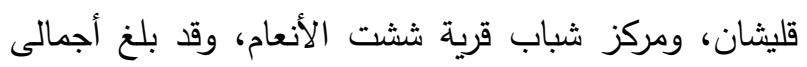
عدد الأعضاء فى مراكز الثباب الثلاثة 1700 ابناباً منهم

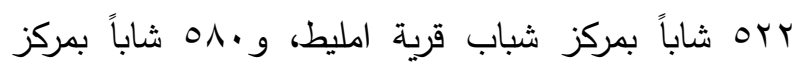

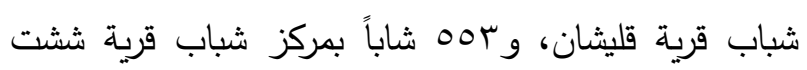

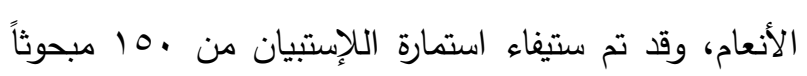
بواقع •0 شاباً (مبحوثاً) من كل مركز تم إختيارهم بطريقة عشوائية من واقع سجلات العضوية القائمة بتلك المراكز . تجميع وتحليل البيانات وتم جمع البيانات باستخدام الاستبيان بالمقابلة الشخصية

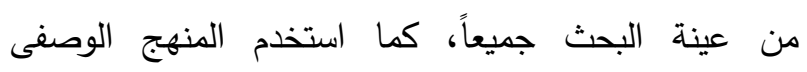
التحليلى فى إجراء البحث، وتم استخدام النسبة المئوية، والجداول التكرارية، ومعاملات الارتباط البسيط لبيرسون، وأسلوب التحليل الإنحدارى المتعدد بالإضافة، وقد تم استيفاء بيانات إستمارة الإستبيان فى الفترة من (أول يوليو إلى نهاية

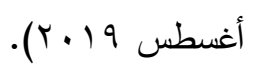

\section{النتائج البحثية}

أظهرت النتائج الواردة بجدول (1) أن: سن والد المبحوث (سنة): تراوح سن والد الشباب المبحوثين

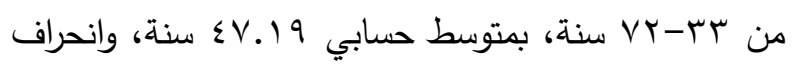

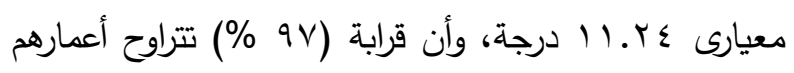

القرية وتثجير الطرق الرئيسية بها، وتثجير مقابرها، ودهان واجهات المنازل، والتخلص من المخلفات الزراعية والمنزلية وإعادة تدويرها، وتوسيع الطرق بين المزارع، أو ودات

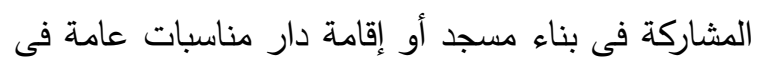

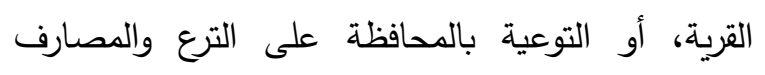
والمحافظة على البيئة. والدعاية للحملات القومية المعنية ببرامج تحصين الأطفال والحيوانات من الأمراض، وذلك وائك على مقياس ثلاثى متدرج من (لم يشارك - يشارك بشكل

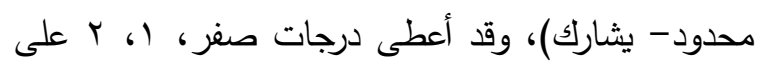

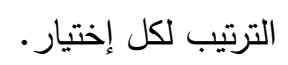
الفرض الأول: يتأثر الإتجاه نحو العمل الزراعى للشباب

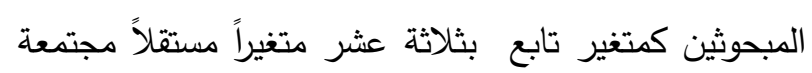

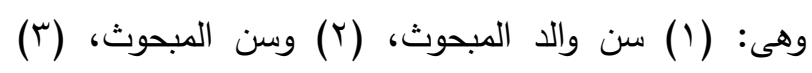

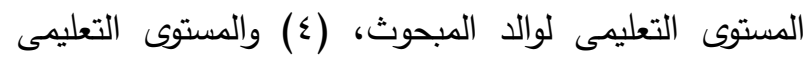
للمبحوث، (0) وعدد أفراد الأسرة، (T) والحيازة الأرضية

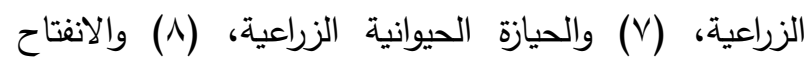

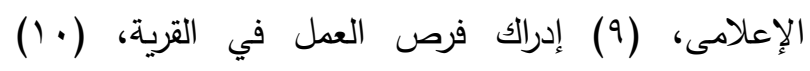

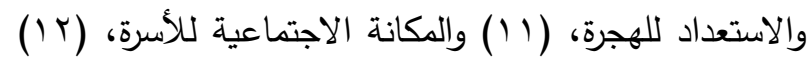

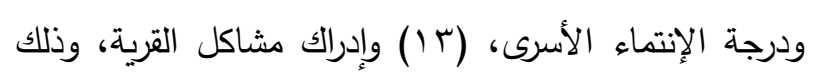
فى ظل التأثيرات التبادلية لهذه المتغيرات. وقد تم قياس الفرض السابق فى صورته الصغرية التى تتص على عدم وجود علاقة بين المتغير التابع، والمتغيرات المستقلة المدروسة.

الفرض الثانى: تتأثر المشاركة في أنشطة خدمة البيئة الريفية للشباب المبحوثين كمتغير تابع بثلاثة عشر متغيراً مستقلاً

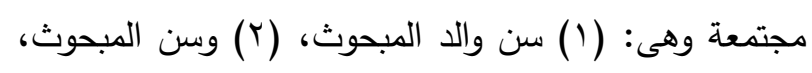

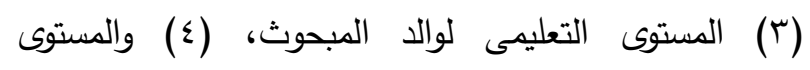
التعليمى للمبحوث، (0) وعدد أفراد الأسرة، (†) والحيازة

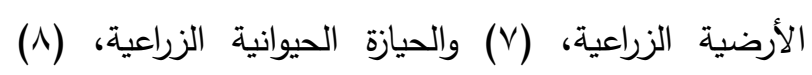

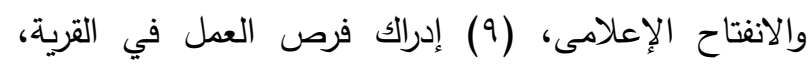
(· (1) والاستعداد للهجرة، (1) والمكانة الاجتماعية للأسرة، 
الزراعية التي تملكها معظم أسر المبحوثين، حيث أن معظم الأسر (^\%) لديهم حيازات صغيرة ومتوسطة.

الحيازة الحيوانية: تراوح عدد الوحدات الحيوانية الخاصة بأسر المبحوثين من (1- 10 وحدة حيوانية)، بمتوسط

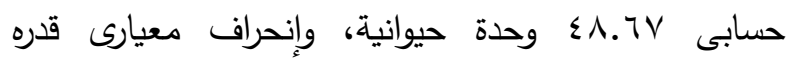
• . . . . د درجة، وبلغت نسبة ذوى عدد الوحدات الحيوانية

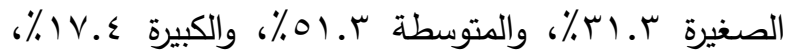
من جملة عدد المبحوثين. الإنفتاح الإعلامي: تراوحت القيم الرقمية المعبرة عن الإنفتاح الإعلامى للمبحوثين من س- 1 ا إلدة درجة، بمتوسط حسابى قدره

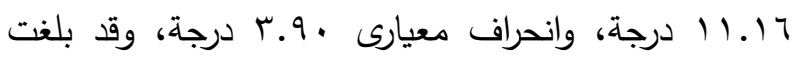

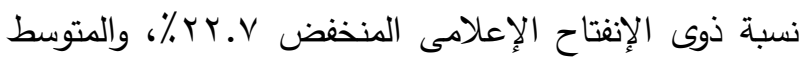

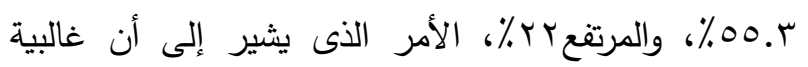

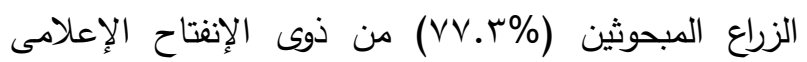
المتوسط والمرتفع. إدراك فرص العمل في القرية: تراوحت القيم الرقمية المعبرة عن إدراك المبحوثين لفرص العمل في القرية من •- ؛ درجات، بمتوسط حسابى قدره 9 1. ب درجة، وانحراف معيارى گr. ا درجة، وقد بلغت نسبة ذوى الإدراك المنخفض

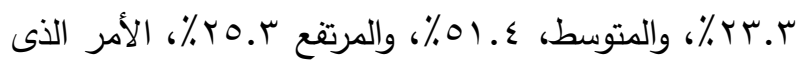

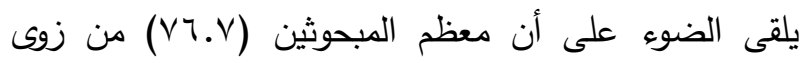
الأدراك المتوسط والمرتفع.

الاستعداد للهجرة: تراوحت القيم الرقمية المعبرة عن استعداد

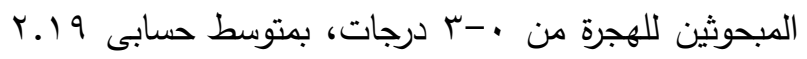

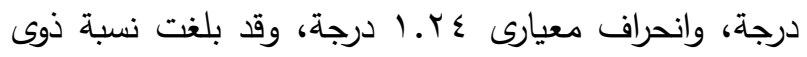
الاستعداد المنخفض r.r.

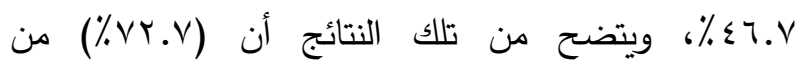
المبحوثين لديهم استعداد متوسط ومرتفع للهجرة. المكانة الإجتماعية للأسرة: تراوحت القيم الرقمية المعبرة عن المكانة الإجتماعية لأسر المبحوثين من ا-ب درجة، بمتوسط لراعله

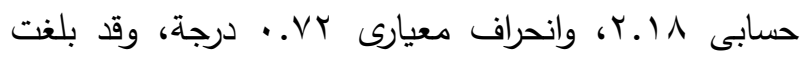

ما بين ــ-0ه سنه. أى أن معظم الزراع المبحوثين فى

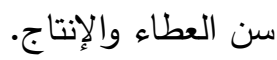

سن المبحوث (سنة): تراوح سن الثباب المبحوثين من 0 1-

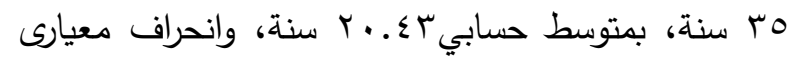

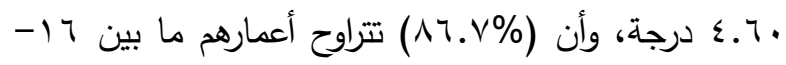
هب سنه. أى أن الثباب المبحوثين فى السن الذى يسمح لهم ببذل الجهد والمساهمة في الأنشطة المختلفة لحماية البيئة.

المستوى التعليمي لوالد المبحوث: تراوح المستوى التعليمى لوالد المبحوثين ما بين أمى إلى حاصل على التعليم

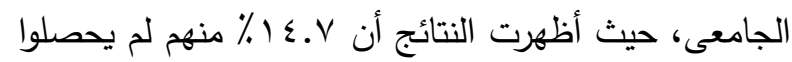

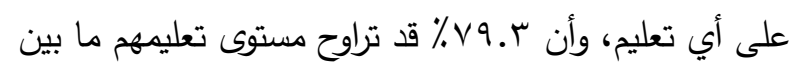
قادر على القراءة والكتابة وحاصل على الثانوية العامة، وأن 7\% منهم قد حصل على تعليم جامعى. المستوى التعليمي المبحوث: أظهرت النتائج أن ب٪ من المبحوثين لم يحصل أى منهج على أي نوع من التعليم، وأن ץ.ب^\% قد تراوح مستوى تعليمهم ما بين قادر على القراءة

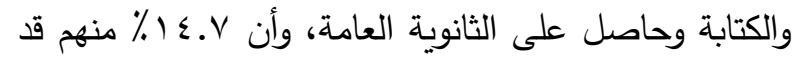
حصل على تعليم جامعى. عدد أفراد الأسرة: تراوح عدد أفراد أسرة المبحوث ما بين ץ9 أفراد بمتوسط حسابى بلغ سم.0 فرد، وإنحراف معيارى

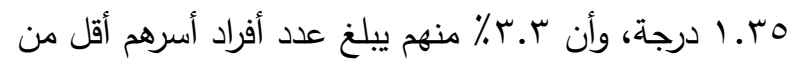

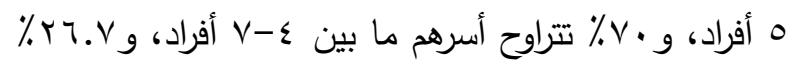
يزيد عدد أفراد أسرهم عن V أفراد.

الحيازة الأرضية الزراعية: تراوحت الحيازة الأرضية الزراعية لاى أسر المبحوثين من صفر إلى سبا قيراط، بمتوسط الإدها

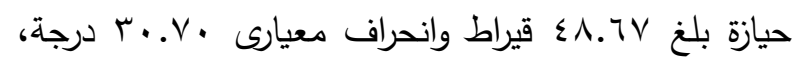

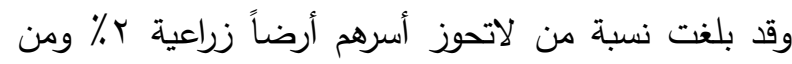

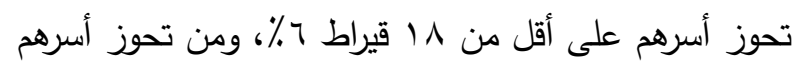

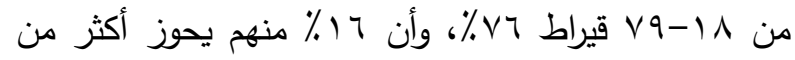
V9 قيراط، الأمر الذى يثير إلى صغر حجم المساحة 
123 محمد صبري مصطفي محمد صالح: اتجاهات الثباب الريفي نحو العمل الزراعي والمشاركة في أنشطة خدمة البيئة الريفية....

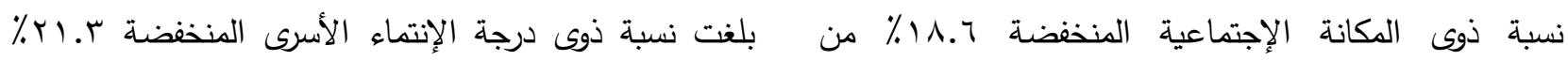

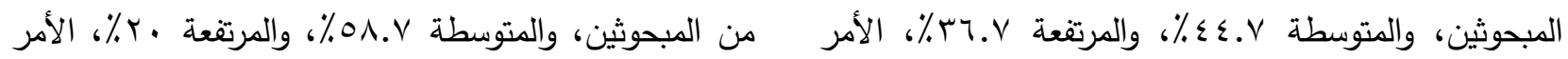

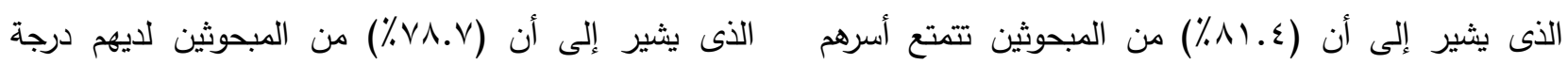

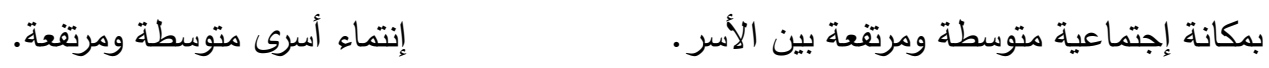
درجة الإنتماء الأسرى: تراوحت القيم الرقمية المعبرة عن درجة الإنتماء الأسرى بين المبحوثين من ع-7 الإسماء درجة،

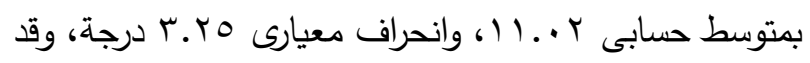

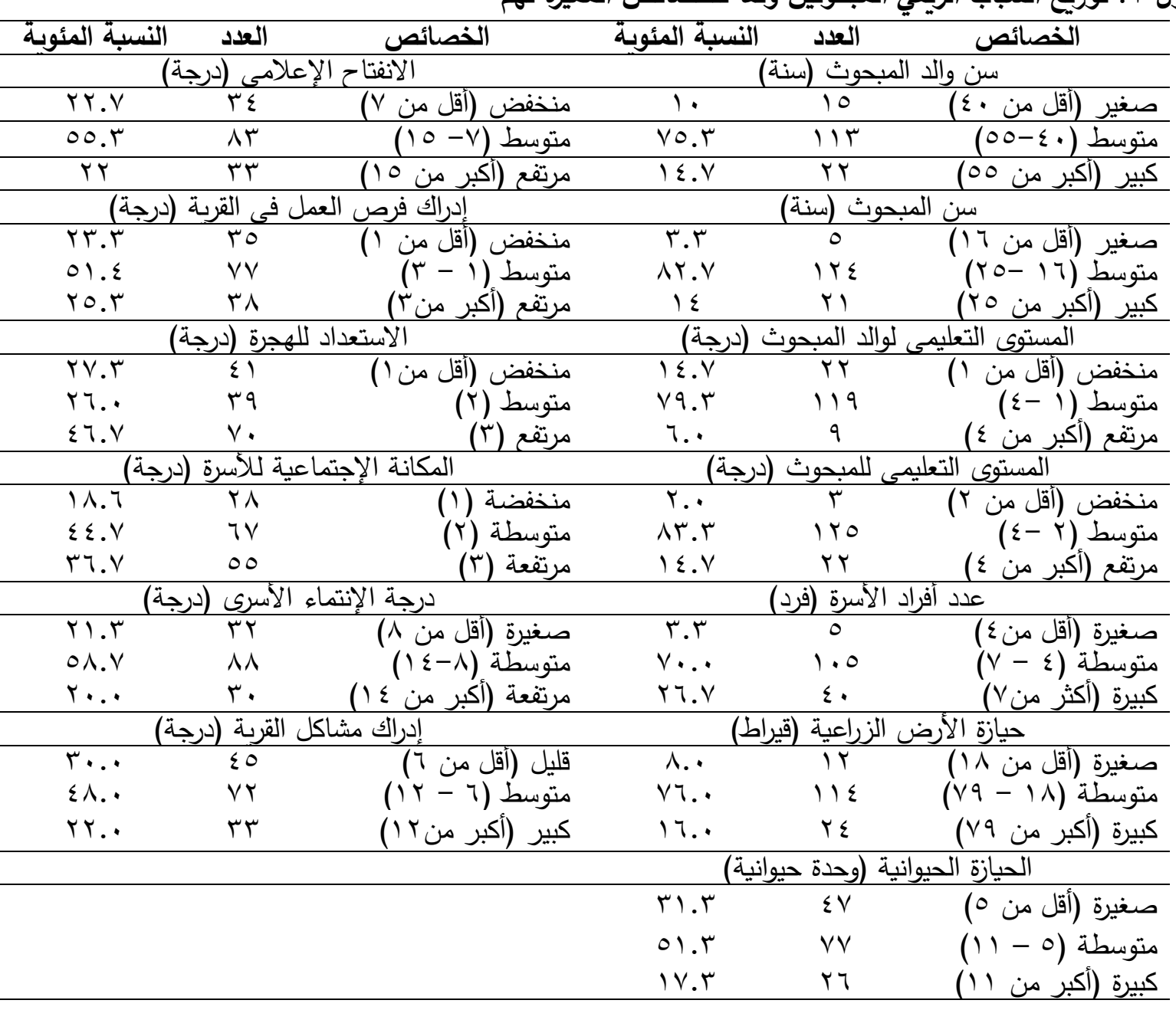


ضرورة توجيه وتوعية هؤلاء الثباب لأهمية وقيمة العمل الزراعى وتغيير الاتجاهات السلبية وتعديل الإتجاهات المحايدة، وتدعيم الإتجاهات الإيجابية.

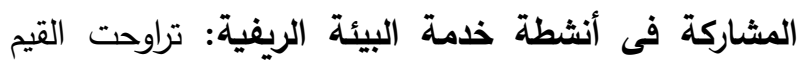

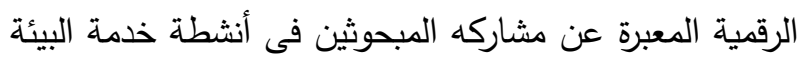

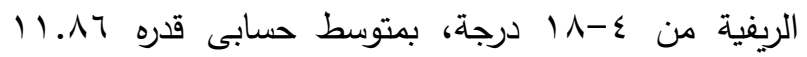
درجة، وانحراف معيارى 10.؛ درجة، وقد بلغت نسبة ذوى

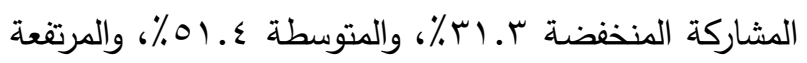

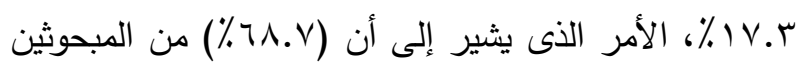

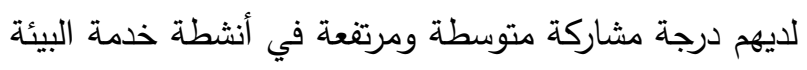

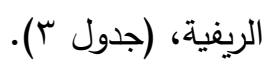

إدراك مشاكل القرية: تراوحت القيم الرقمية المعبرة عن إدراك

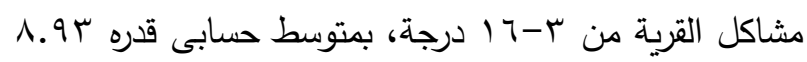

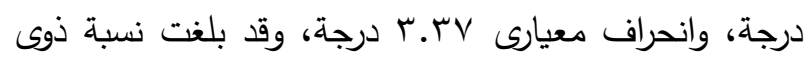

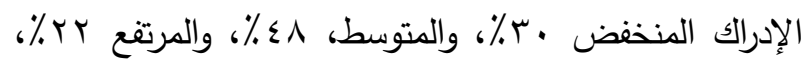

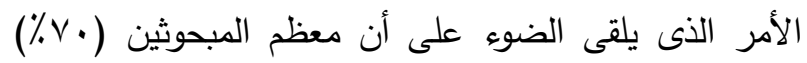
من ذوى الإدراك المتوسط والمرتفع. الإتجاهات نحو العمل الزراعى: تراوحت القيم الرقمية المعبرة

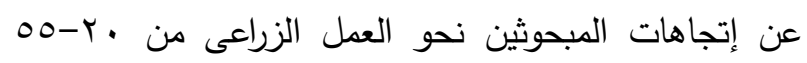

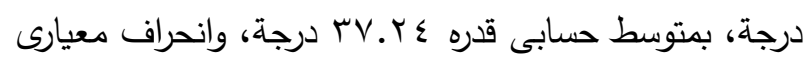

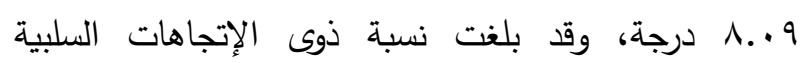

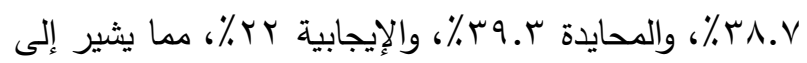

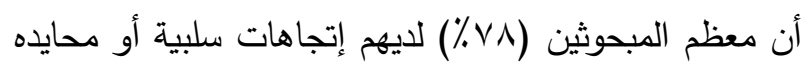

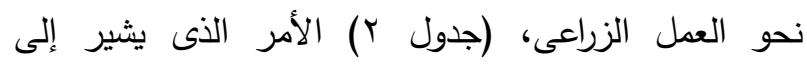

جدول r . توزيع المبحوثين وفقاً لفئات إتجاهاتهم نحو العمل الزراعى

\begin{tabular}{|c|c|c|}
\hline النسبة المئوبـة & العدد & فئات الاتجاه (درجة) \\
\hline rᄉ.V & $0 \Lambda$ & سلبى (أقل من 9 Y) \\
\hline rq.r & 09 & محايد (q צ-0 §) \\
\hline rr.. & rr & إيجابى (أكثر من 0؛) \\
\hline $1 \ldots$ & 10. & المجموع \\
\hline
\end{tabular}

جدول r. توزيع المبحوثين وفقا لفئات مشاركتهم فى أنثطة خدمة البيئة الريفية

النسبة المئوية

ए.r

$01 . \varepsilon$

IV.r
العدد الرئية

$\varepsilon \vee$

V

rт فئات المشاركة (درجة)

منخفضة (أقل من V) متوسطة (lv- ( )

مرتفعة (أكثر من VV) 
125 محمد صبري مصطفي محمد صالح.: اتجاهات الثباب الريفي نحو العمل الزراعي والمشاركة في أنشطة خدمة البيئة الريفية....

وللتعرف على أكثر المتغيرات المستقلة تأثيراً فى المتغير التابع فقد أجرى التحليل الإنحدارى المتعدد خطوة خطوة بين المتغير التابع والمتغيرات المستقلة ذات الإرتباط المعنوى مع إلى

$$
\text { المتغير التابع، ومن ثم تبين ما يلى: }
$$

أوضحت نتائج التحليل الإنحدارى المتعدد خطوة خطوة stepwise multiple regression analysis متغيرات مستقلة فقط هم الأكثر تأثيراً فى الإتجاه نحو العمل الزراعى بين الثباب المبحوثين كمتغير تابع وهم على الترتيب التتازلى وفقاً لنسبة إسهامها فى المتغير التابع: الاستعداد للهجرة، وإدراك فرص العمل، ودرجة الإنتماء الأسرى، وحيازة الأرض الزراعية، وإدراك مشاكل القرية، وأن هذه المتغيرات

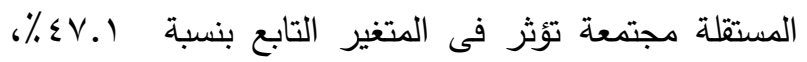

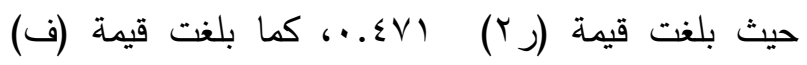
1 \.7 وهى قيمة معنوية عند المستوى الاحتمالى ا ل... (جدول 0)، الأمر الذي يؤكد أن هناك متغيرات مستقلة أخرى تؤثر على الإتجاه نحو العمل الزراعى بين الثباب المبحوثين لم يتتاولها هذا البحث، ويمكن أن تتناولها أبحاث مستقبلية

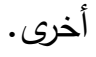

كما توضـح بيانات جدول (0) أن متغير الاستعداد للهجرة

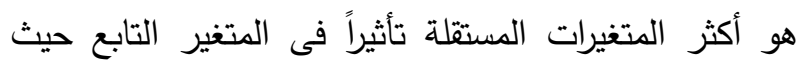

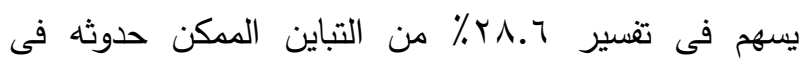
المتغير التابع، يليه متغير ادراك فرص العمل ويسهم بنسبة

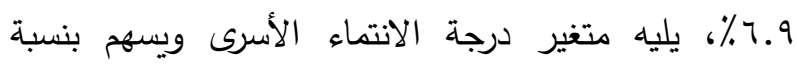

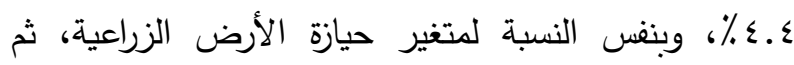
متغير إدراك مشاكل القرية، ويسهم بنسبة ^.؟\% فقط من التباين الممكن حدوثه فى المتغير التابع فى ظل وجود باقى المتغيرات المستقلة الداخلة فى التحليل، (جدول ه).
العلاقات الارتباطية والإنحدارية بين الإتجاه نحو العمل الزراعى كمتغير تابع وكل من المتغيرات المستقلة المدروسة لكي يتسنى التعرف على المتغيرات المستقلة المؤثرة فى الإتجاه نحو العمل الزراعى بين الثباب المبحوثين قام الباحث بدراسة العلاقات الارتباطية البسيطة بين الإتجاه نحو العمل الزراعى كمتغير تابع وكل من المتغيرات المستقلة، ومن ثم

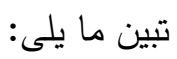

أوضحت نتائج التحليل الإرتباطى البسيط (معامل ارتباط

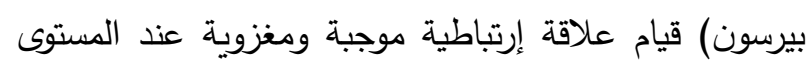
الاحتمالى ا ... بين الإتجاه نحو العمل الزراعى كمتغير تابع وكل من المتغيرات المستقلة الآتية كل على حده: حيازة الأرض الزراعية، وحيازة الحيوانات الزراعية، والإنفتاح الإعلامى، وإدراك فرص العمل بالقرية، ودرجة الإنتماء الأسرى، وإدراك مشاكل القرية، بينما كانت تلك العلاقة موجبة ومعنوية عند المستوى الاحتمالى ه . . مع المتغير المستقل المستوى التعليمى لوالد المبحوث، ومؤدى ذلك ان المتغير التابع متلازم فى تغيره وفى نفس الاتجاه مع التغير فى كل

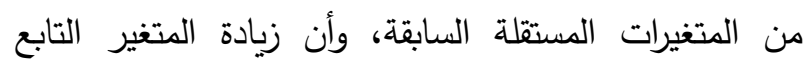
يصاحبها زيادة فى كل من المتغيرات المستقلة والعكس بالعكس.

كما أوضحت النتائج البحثية قيام علاقة إرتباطية سلبية بين المتغير التابع والمتغير المستقل الاستعداد للهجرة، ومؤدى ذلك أن المتغيرين متلازمان ويتحركان معاً فى اتجاهين متضادين، أى أن زيادة أحدهما يصاحبها نقص فى المتغين فئنير

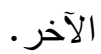

كما بينت النتائج البحثية عدم قيام علاقة إرتباطية معنوية بين المتغير التابع وكل من سن المبحوث، وسن والد المبحوث، والمستوى التعليمى للمبحوث، وعدد أفراد الأسرة،

والمكانة الإجتماعية للأسرة، كمتغيرات مستقلة، (جدول ؟). 
جدول ؛ . نتائج التحليل الإرتباطى بين الإتجاه نحو العمل الزراعى كمتغير تابع وكل من المتفيرات المستقلة

\begin{tabular}{|c|c|c|c|}
\hline معامل الارتباط & المتغيرات المستقلة & معامل الارتباط & المتغيرات المستقلة \\
\hline$* * \cdot . Y .9$ & الإنفتاح الإعلامى & $. .099-$ & سن والد المبحوث \\
\hline$* * \ldots 乞 \wedge \Lambda$ & إدراك فبرص العمل & $\ldots 10$ & سن المبحوث \\
\hline ***. & الاستعداد للهجرة & $* . .194$ & المبحوث التعليمى لوالد \\
\hline$\ldots \vee 9$ & المكانة الإجتماعية & $\ldots v V$ & المستوى التعليمى للمبحوث \\
\hline ***. . r Y O & درجة الإنتماء الأسرى & $\ldots 1 \mathrm{~V}$ & عدد آفراد الأسرة \\
\hline ** $\cdot$. rYY & إدراك مشاكل القرية & 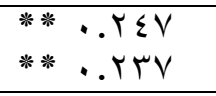 & حيازة الحيوانات الزياعراعية \\
\hline
\end{tabular}

جدول ه. نتائج التحليل الإنحارى المتعدد بالإضافة بين الإتجاه نحو العمل الزراعى كمتغير تابع والمتغيرات المستقلة

\begin{tabular}{|c|c|c|c|c|c|}
\hline المعنوية & ف & المفبة التراكمية للتباين & التباينة المتركمية & المتفيرات الداخلة فى & الخطوة \\
\hline$\ldots 1$ & $\wedge 9.49$ & YA.T & r৯. & الاستعداد للهجرة & 1 \\
\hline$\ldots 1$ & $\{. . \leq \leqslant 7$ & 7.9 & ro.o & ادرالك فرص العمل & r \\
\hline$\ldots 1$ & Tr.TIQ & $\varepsilon . \varepsilon$ & r9.9 & درجة الإنتماء الأسرى & r \\
\hline$\ldots 1$ & 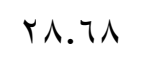 & $\varepsilon . \varepsilon$ & $\varepsilon \varepsilon . r$ & الزيازة الأرض & $\varepsilon$ \\
\hline$\ldots 1$ & r... & Y.A & $\sum V_{.} 1$ & إدراك مشاكل القربة & 0 \\
\hline
\end{tabular}

كمتغير تابع وكل من المتغيرات المستقلة الآتية كل على

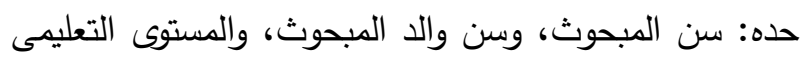

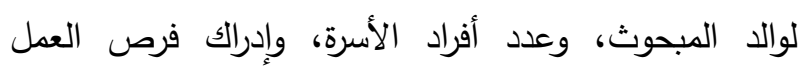

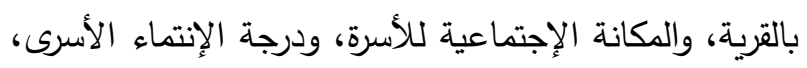

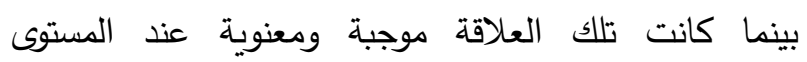
الاحتمالى ه... مع متغير واحد فقط وهو إدراك مشاكل القرية، ومؤدى ذلك ان المتغير التابع متلازم فى تغيره وفى التى

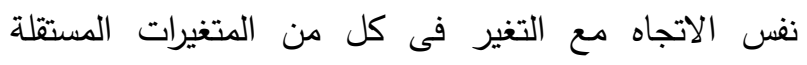

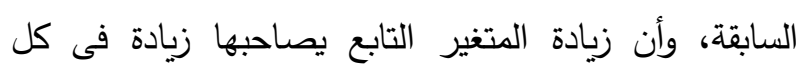
المتغيرات المستقلة والعكس بالعكس.
العلاقات الارتباطية والإنحدارية بين المشاركة فى أنثطة خدمة البيئة كمتغير تابع وكل من المتغيرات المستقلة المدروسة

لكى يتسنى التعرف على المتغيرات المستقلة المؤثرة فى المشاركة فى أنشطة خدمة البيئة قام الباحث بدراسة العلاقات التئن الارتباطية البسيطة بين المشاركة فى أنثطة خدمة البئئة

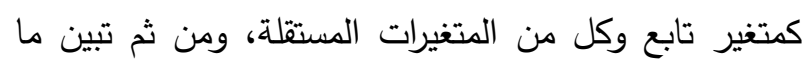
أوضحت نتائج التحليل الإرتباطى البسيط (معامل ارتباط

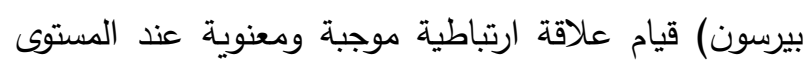
الاحتمالى ا... بين المشاركة فى أنثطة خدمة البيئة 
127 محمد صبري مصطفي محمد صالح.: اتجاهات الثباب الريفي نحو العمل الزراعي والمشاركة في أنشطة خدمة البيئة الريفية....

جدول 1.

\begin{tabular}{|c|c|c|c|}
\hline معامل الارتباط & المتغيرات المستقلة & معامل الارتباط & المتغيرات المستقلة \\
\hline $.11 \pi-$ & الإنفتاح الإعلامى & $* * . r \wedge \wedge$ & سن والد المبحوث \\
\hline$* * . . T V Y$ & إدراك فرص بالقرية العمل & $* * . .4 q q$ & سن المبحوث \\
\hline$* * \cdot Y \cdot V-$ & الاستعداد للهجرة &. .09 & المستوى التعليمى لوالد \\
\hline$* * .0 r r$ & المكانة الإجتماعية & $* * .7 \leq 1$ & المستوى التعليمى للمبحوث \\
\hline$* * .07 \mu$ & درجة الإنتماء الأسرى & $* * . . \mathrm{YVV}$ & عدد أفراد الآسرة \\
\hline \multirow[t]{2}{*}{$* . .194$} & إدراك مشاكل القرية & $* .109-$ & حيازة الأرض الزراعية \\
\hline & & $* * . . Y q \mid-$ & حيازة الحيوانات الزراعية \\
\hline
\end{tabular}

لنسبة إسهامها فى المتغير التابع: المستوى التعليمى للمبحوث، ودرجة الإنتماء، والمكانة الإجتماعية للأسرة، وسن

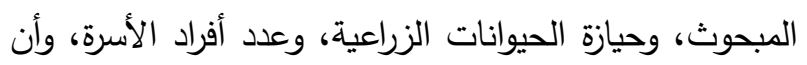

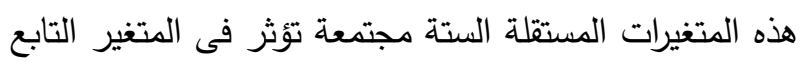

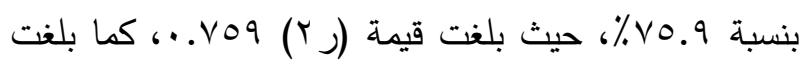

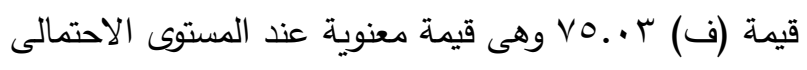
I...، (جدول). الأمر الذي يؤكد أن هناك متغيرات مستقلة أخرى تؤثر على الإتجاه نحو العمل الزراعى بين الثباب المبحوثين لم يتتاولها هذا البحث، ويمكن أن تتناولها أبحاث مستقبلية أخرى. - ابثن

كما توضح بيانات جدول (V) أن متغير المستوى

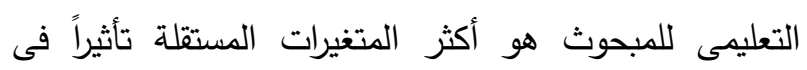

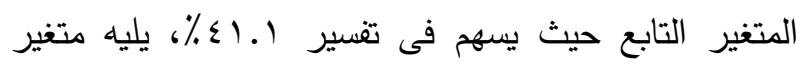

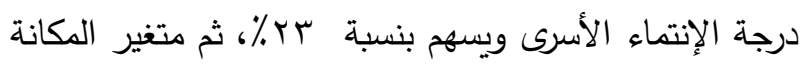

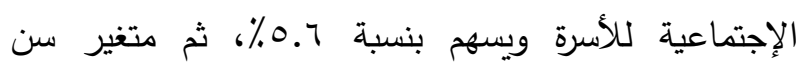
المبحوث ويسهح بنسبة . .ء٪٪، يليه متغير حيازة الحيوانات الزراعية ويسهح بنسبة ؟. ٪\%، وأخيراً متغير عدد أفراد الأسرة

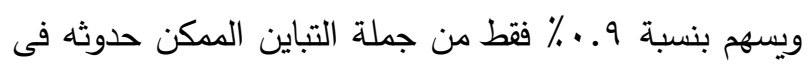
المتغير التابع فى ظل وجود باقى المتغيرات المستقلة الداخلة

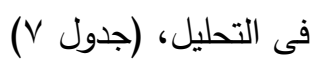

كما أوضحت النتائج البحثية قيام علاقة إرتباطية سلبية بين المتغير التابع وكل من المتغيرين المستقلين حيازة

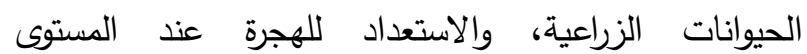
الاحتمالى ا .... بينما كانت تلك العلاقة سلبية ومعنوية عند

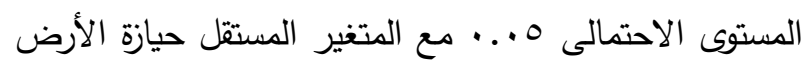
الزراعية، ومؤدى ذلك ان المتغير التابع متلازم فى تغيره وفى التى عكس اتجاه تغير المتغيرات المستقلة السابقة، وأن زيادة المتغير التابع يصاحبها تغير فى عكس الاتجاه فى كل من تنير

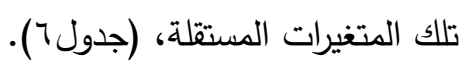
كما بينت النتائج البحثية عدم قيام علاقة ارتباطية معنوية بين المتغير التابع وكل من المستوى التعليمى لوالد المبحوث، لئه والإنفتاح الإعلامى كمتغيرين مستقلين، (جدول 7). وللتعرف على أكثر المتغيرات المستقلة تأثيراً فى المتغير التابع فقد أجرى التحليل الإنحدارى المتعدد خطوة بخطوة بين المتغير التابع والمتغيرات المستقلة ذات الإرتباط المعنوى مع الإنى المتغير التابع، ومن ثم تبين ما يلى:

أوضحت نتائج التحليل الإنحدارى المتعدد خطوة بخطوة stepwise multiple regression analysis متغيرات مستقلة فقط هم الأكثر تأثيراً فى المشاركة فى أنشطة خدمة البيئة كمتغير تابع، وهى على الترتيب التتازلى وفقا 
جدول V. نتائج التحليل الإنحدارى المتعدد بالإضافة بين المتغيرات المستقلة ومشاركة المبحوثين فى أنثطة خدمة البيئة

\begin{tabular}{|c|c|c|c|c|c|}
\hline \multicolumn{6}{|c|}{ كمتغير تابع } \\
\hline المعنوبة & ف & المفنبة التراكمية للتباين التبعي & للتباينة المفركية & المتغيرات الداخلة فى & الخطوة \\
\hline$\cdots+1$ & $1 \cdot 4.11$ & $\leqslant 1.1$ & $\varepsilon 1.1$ & المستوى التعليمى & 1 \\
\hline$\ldots 1$ & $1 T \cdot .9 V V$ & rT.. & $7 \varepsilon .1$ & درجة الإنتماء الأسرى & r \\
\hline$\cdot .+1$ & $11 \% \ldots 0$ & 0.7 & 79.8 & المكانة الإجتماعية & $\mu$ \\
\hline. .1 & 1.1 .790 & $\varepsilon \ldots$ & VT.V & سن المبحوث & $\varepsilon$ \\
\hline$\cdots 1$ & AT.rYo & $1 . r$ & vo.. & حيازة الحيوانات & 0 \\
\hline$\cdots+1$ & $V 0 . . T \leq$ & .99 & $v 0.9$ & عدد أفراد الأسرة & 7 \\
\hline
\end{tabular}

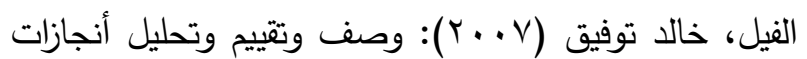

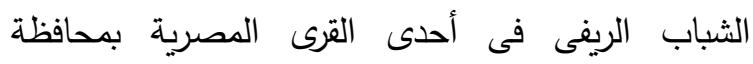

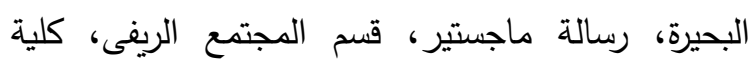

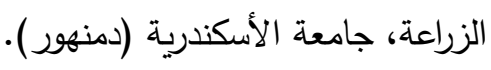

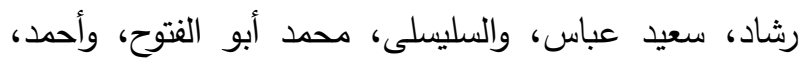

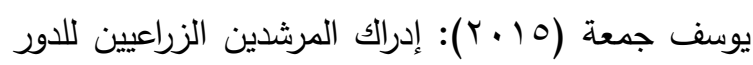
الحالي للإرشاد الزراعى في الدحافظة علي البيئة الزراعية من التلوث في ظل سياسة التحرر الاقتصادي، مجلة

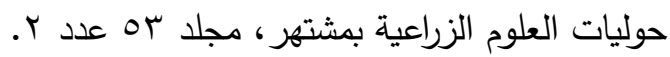

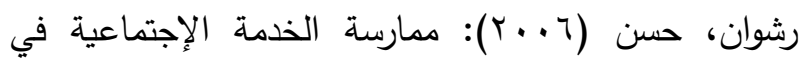

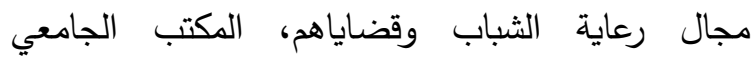
الحديث، القاهرة.

رضوان، نادية (999)): الثباب المصري المعاصر وأزمة القيم، الهيئة المصرية العامة للكتاب. عبد الله، محمود عبد الحميد (1991): القيم البيئية لدى

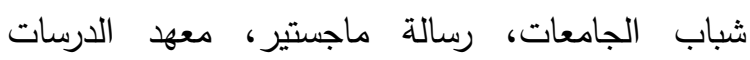
والبحوث البيئية، جامعة عين شمس.

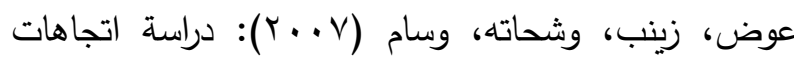
الثباب الريفى نحو العمل فى مجال الزراعة بمحافظتى

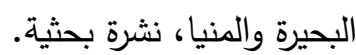

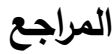

أبو السعود، محمد أبو السعود ربيع (Y + Y): التضضيلات

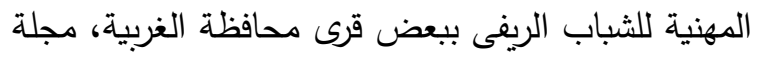

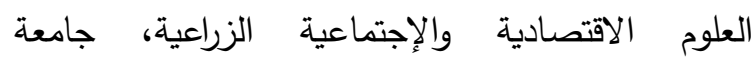

$$
\text { المنصورة، العدد ז، مجلد با. }
$$

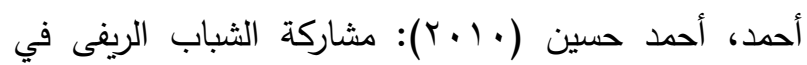

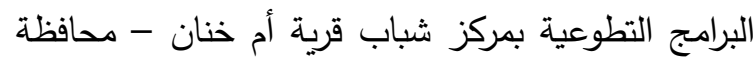
T أكتوبر، رسالة دكتوراه، قسم الإجتماع الريفى والإرشاد الزراعى، كلية الزراعة، جامعة القاهرة.

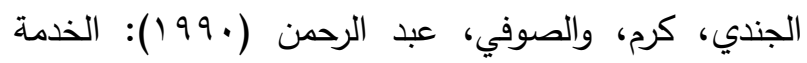

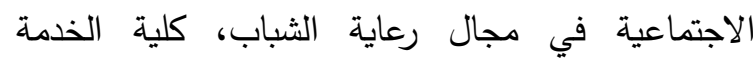
الاجتماعية، جامعة حلوان، القاهرة.

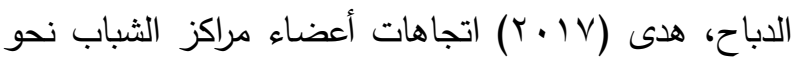
العمل الزراعى ببعض قرى مركز دمنهور فى محافظة

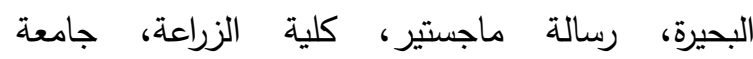
الأسكندرية. الصندوق الدولي للتمية الزراعية (9 (ب): تقرير التتمية

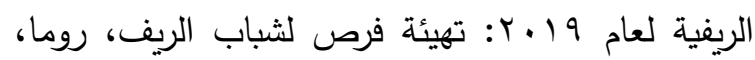
إيطاليا. 
محمد صبري مصطفي محمد صالح.: اتجاهات الثباب الريفي نحو العمل الزراعي والمشاركة في أنشطة خدمة البيئة الريفية....

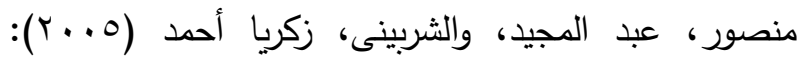

$$
\begin{aligned}
& \text { الثباب بين صراع الأجيال المعاصر والهدى الإسلامي " } \\
& \text { المشكلات القضايا مهارات الحياة، القاهرة، دار الفكر } \\
& \text { العربي. }
\end{aligned}
$$

Mahmoud, Y. A (2009): The level of knowledge to farmers orchards damages Side when using excess fertilizer, Journal of the Iraqi Agricultural Science, vol 40.

$$
\begin{aligned}
& \text { غانم، مصطفى حمدي (ع^9 ()): دراسة تحليلية لاتجاهات } \\
& \text { وقيم الثباب نحو بعض مشروعات التنمية المحلية بريف } \\
& \text { محافظة أسيوط، رسالة ماجستير، قسم الاجتماع الريفى } \\
& \text { والإرشاد الزراعى، كلية الزراعة، جامعة أسيوط. } \\
& \text { كمال، محمد شفيق (9 . . r): مشاركة الشباب الريفى في } \\
& \text { البرامج التطوعية بمركز شباب قرية أم خنان - محافظة }
\end{aligned}
$$

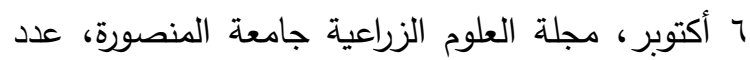

$$
\begin{aligned}
& \text { ع ז، مجلد rا. }
\end{aligned}
$$

\section{ABSTRACT \\ Rural youth Attitudes Toward Agricultural Work, And participation in Rural environment services activities, in Ity Elbaroud District, Behaira Governorate Mohamed Sabry Moustafa Saleh}

The study is mainly aiming to study Rural youth Attitudes Toward Agricultural Work And participate in Rural environment services activities, this will be achieved through the following objectives:

1. Studying some socio, economic, psychological and communication variables of the researched rural youth.

2. Identifying studied rural youth attitudes Toward Agricultural Work.

3. Identifying studied rural youth participate in Rural environment services activities.

4. Identifying the variables correlated and Affecting with the rural youth Attitudes Toward Agricultural Work and participate in Rural environment services activities.

Data was collected using a questionnaire through personal interview for a random sample of 150 subjects, the study used number of statistical methods including percentages, means, frequencies, standard deviation, coefficient of variation, simple correlation, and multiple regression analysis.
The most important results are summarized as follows:

- About (47.1\%) of the variance in the rural youth Attitudes Toward Agricultural Work can be explained by (5) independent variables " immigration Readiness (28.6\%), Perceived work opportunities $(6.9 \%)$, Family belonging (4.4\%), Possession of agricultural land $(4.4 \%)$, and perceive village problems $(2.8 \%)$ ".

- About $(75.9 \%)$ of the variance in the rural youth Attitudes Toward participate in activities to preserve the rural environment can be explained by (6) independent variables "Educational level (41.1), Family belonging (23.0\%), social family position (5.6\%), respondent's age (4.0\%), Possession of farm animals (1.3\%), and Number of Family Members $(0.9 \%) "$.

Keywords: rural youth, Agricultural Work, and environment services activities 